Family Profile No. 21, 2019

\title{
Resident Single Parents: Mothers \& Fathers
}

\section{Author: Colette Allred}

The diversity of family types has increased in the United States, with a decreasing share of children living with two married biological parents (Brown, Manning, \& Stykes, 2015; FP-17-15). In 2017, one-quarter of children under age 18 lived with a single parent, with 15 million children living with a single mother, and 3 million children living with a single father (FP-17-17; Pew 2018). In this Family Profile, we focus on parents who are raising children alone, with no spouse or partner living in their home. We use the 2018 Current Population Survey to identify the prevalence of single parenthood among resident parents and examine their demographic characteristics including gender, educational attainment, and race/ethnicity. We define single parents as men and women aged 18 and older who live with at least one child (under age 18) of their own and who do not live with a spouse or cohabiting partner. This Family Profile joins previously published profiles that explore and document family structure in the United States (FP-17-15; FP-17-16; FP-17-17; FP-18-06; FP-19-01; FP-19-02; FP-19-09).

\section{Resident Single Parents Over A Decade}

- Over the last decade, approaching one in five resident mothers was single, and $4 \%$ of resident fathers were single.

- A higher share of resident mothers were single (not married or cohabiting) than resident fathers at both time points.

- The gender gap for single parenthood is essentially unchanged between 2008 and 2018.

Figure 1. Share of Resident Parents Who Were Single, 2008 \& 2018

Mothers Fathers

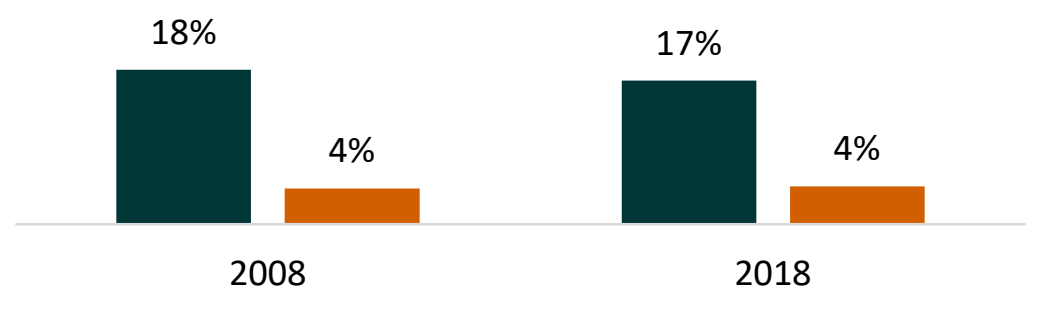

Source: NCFMR Analysis of Current Population Survey, 2008 \& 2018

\section{Resident Single Parents by Educational Attainment}

- About one in five resident mothers with less than a high school degree, high school degree, or some college education was a single mother. A much smaller share of resident fathers with the same education levels were single $(4 \%, 6 \%$, and $5 \%$, respectively) .

- Resident parents with at least a Bachelor's degree were less often single parents. Only one in ten college educated mothers and $3 \%$ of college educated fathers were single.

- The share of resident parents who were single varied more by educational attainment for mothers than for fathers.
Figure 2. Share of Resident Parents Who Were Single Parents in 2018, by Educational Attainment

Mothers Fathers

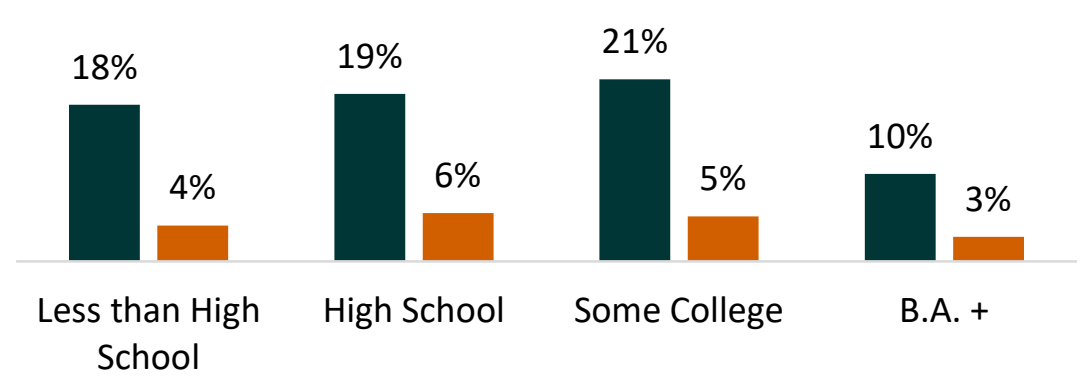

Source: NCFMR Analysis of Current Population Survey, 2018 


\section{Resident Single Parents by Race \& Ethnicity}

- The highest share of resident mothers and fathers who were single was observed among Black parents. Among Black mothers and fathers who lived with their children, $37 \%$ and $8 \%$ were single, respectively.

Figure 3. Share of Resident Parents Who Were Single Parents n 2018, by Race \& Ethnicity

Mothers $\quad$ Fathers

The share of White and Hispanic resident fathers who were single (4\%) was half the level observed among Black resident fathers.

- A higher share of Hispanic resident mothers were single (20\%) in comparison to White $(12 \%)$ resident mothers.

- The share of resident parents who were single varied more by race and ethnicity for mothers than for fathers.

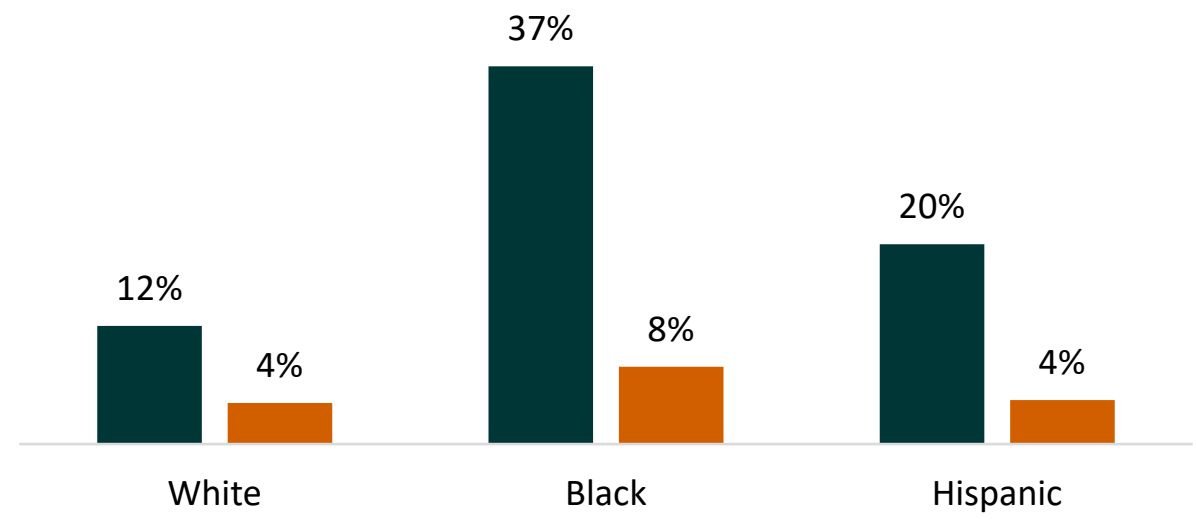

Source: NCFMR Analysis of Current Population Survey, 2018

\section{Data Sources:}

Flood, S., King, M., Ruggles, S., and Warren J. R. Integrated Public Use Microdata Series, Current Population Survey: Version 6.0 [2018 CPS]. Minneapolis, MN: IPUMS, 2018. https://doi.org/10.18128/D030.V6.0

\section{References:}

Brown, S. L., Manning, W. D., \& Stykes, J. B. (2015). Family structure and child well-being: Integrating family complexity. Journal of Marriage and Family, 77(1), 177-190.

Eickmeyer, K. J. (2017). American children's family structure: Two biological parent families. Family Profiles, FP-17-15. Bowling Green, OH: National Center for Family \& Marriage Research. https://www.bgsu.edu/ncfmr/resources/data/family-profiles/eickmeyer-twobiological-parent-families-fp-17-15.html.

Eickmeyer, K. J. (2017). American children's family structure: Stepparent families. Family Profiles, FP-17-16. Bowling Green, OH: National Center for Family \& Marriage Research. https://www.bgsu.edu/ncfmr/resources/data/family-profiles/eickmeyer-stepparentfamilies-fp-17-16.html.

Eickmeyer, K. J. (2017). American children's family structure: Single-parent families. Family Profiles, FP-17-17. Bowling Green, OH: National Center for Family \& Marriage Research. https://www.bgsu.edu/ncfmr/resources/data/family-profiles/eickmeyer-single-parentfamilies-fp-17-17.html.

Eickmeyer, K. J. (2018). Fathers with resident minor children, 2016. Family Profiles, FP-18-06. Bowling Green, OH: National Center for Family \& Marriage Research. https://doi.org/10.25035/ncfmr/fp-18-06.

Eickmeyer, K. J. (2019). Cohabitors raising shared children. Family Profiles, FP-19-01. Bowling Green, OH: National Center for Family \& Marriage Research. https://doi.org/10.25035/ncfmr/fp-19-01.

Eickmeyer, K. J. (2019). Composition of cohabiting families. Family Profiles, FP-19-02. Bowling Green, OH: National Center for Family \& Marriage Research. https://doi.org/10.25035/ncfmr/fp-19-02.

Pew Research Center. (2018). "The changing profile of unmarried parents." https://www.pewsocialtrends.org/2018/04/25/the-changingprofile-of-unmarried-parents/

Schweizer, V. J. (2019). Characteristics of foster children in the U.S., 2016-2018. Family Profiles, FP-19-09. Bowling Green, OH: National Center for Family \& Marriage Research. https://doi.org/10.25035/ncfmr/fp-19-09.

\section{Suggested Citation:}

Allred, C. (2019). Resident Single Parents: Mothers \& Fathers. Family Profiles, FP-19-21. Bowling Green, OH: National Center for Family \& Marriage Research. https://doi.org/10.25035/ncfmr/fp-19-21 